\title{
Research On The Performance
}

\section{Evaluation of Government Venture \\ Capital Guiding Fund Based On DEA}

\section{Cluster}

\author{
Jianhong Dong ${ }^{1,2,3}$ Hongmei Zhang ${ }^{1,2,3}$ Yongjun Zhou ${ }^{4}$ \\ ${ }^{1}$ Guizhou University of Finance and Economics, Institute of Finance \\ ${ }^{2}$ Guizhou Institution for Technology Innovation \& Entrepreneurship Investment \\ ${ }^{3}$ Guizhou Institute of Urban Economics and Development Guiyang Guizhou \\ 550025, China \\ ${ }^{4}$ Guizhou Bank Headquarters
}

\begin{abstract}
To encourage initial enterprises to be better development, government sets up the venture capital fund through guiding social capital investment and increasing investment in start-up and seed enterprises to speed up the development of enterprises. The purpose of this paper is to study the government effect brought by the venture capital fund performance evaluation, plans to build the index system of government venture capital guiding fund performance evaluation, through DEA clustering method to research 40 government efficiency results of venture capital guiding fund performance ;And the government in the process of direct capital investment need to be aware of inputs, to enhance the capacity of the government performance evaluation of venture capital fund, and to better promote the development of the rapid growth of the start-up.
\end{abstract}

\section{Keywords}

Venture Capital; Guiding Funds; Performance Evaluation; DEA Cluster Method

\section{基于 DEA 聚类的政府创业投资引导基金 绩效评价研究} 董建宏 $1,2,3$ 张红梅 ${ }^{1,2,3}$ 周永俊 4 
1 贵州财经大学, 金融学院; 2 贵州科技创新创业投资研究院; 3 贵州城镇经济与发展 研究院, 贵州 贵阳, $550025 ;{ }^{4}$ 贵州银行总行

摘要：政府为鼓励初创期企业更好发展，设立创业投资引导基金，通过引导社会资本的投入 并加大对初创型、种子型企业投资力度来加快企业的发展。本文旨在研究政府创业投资引导 基金所带来的绩效效果评价，拟构建政府创业投资引导基金绩效评价指标体系，通过 DEA 聚类方法, 研究 40 家政府创业投资引导基金绩效效率结果; 研究政府在引导资本投入的过程 中需要注意的投入要素，为增强政府创业投资引导基金绩效评价能力，更好促进初创型企业 的快速成长发展。

关键词 : 创业投资; 引导基金 ; 绩效评价; DEA 聚类法

\section{1. 引导基金绩效评价研究现状}

\section{1 国外研究现状}

早在 1998 年, Josh Lerner 就从吸 引社会资本的角度针对美国小企业投 资公司（Smal1 Business Investment Corporation, SBIC) 进行了绩效评价。

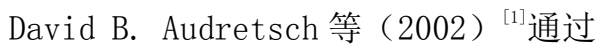
对 SBIC 的绩效进行定性研究, 分析得 出此种绩效评价有助于社会活动的运 行, 并带来实质性的社会效益。

Luukkonen Terttu 等（2013） ${ }^{[2]}$ 通过对 欧洲市场调查研究，发现风投基金投资 效果和效率要远高于政府创业投资基

1作者简介: 张红梅, 教授、硕士生导师, 任职于贵州财经大学金融学院, 研究方向: 金融与区域发展、创业投资、风险分析与管 理。Email: 754560989@qq.com。

董建宏, 男, 贵州财经大学金融学院研究生 硕士。贵州财经大学在读研究生, 研究方向: 金融与区域发展、创业投资、风险分析与管 理。Email: 303519719@qq.com 周永俊, 现就职于贵州银行总行人力资源部 任招聘主管,Email: 13765036256@126.com。
金, 主要是对双方进行绩效评价研究, 对比分析被投资企业运营状况和发展。

国外的投资研究表明在政府创业 投资引导基金的投资效率和结果上有 待进一步优化，政府创业投资引导基金 的绩效评价指标体系需要科学地构建。

\section{2 国内研究现状}

我国政府创业投资引导基金的绩 效评价问题是如今多数国内外学者研 究的主要议题, 可如何利用有效的分析 评价方法来构建整个绩效评价体系还 有待继续研究探索。李洪江、鲍晓燕 （2011） ${ }^{[3]}$ 在政府创业投资引导基金的 政策效应一块, 明确指出了绩效评价的 价值取向, 重点强调需以政策效应为核 心来加以导向，从而构建政府创业投资 引导基金的绩效评价指标体系。石琳 （2013） ${ }^{[4]}$ 在构建创业投资引导基金绩 效评价模型的时候指出了模型的设计 思路、指标的耖选、指标权重的确定及 模糊综合评价的运用, 并对上海市创业 投资引导基金进行了绩效评价研究。王 哲、张红梅（2015） ${ }^{[5]}$ 通过运用因子分 
析法分析在政府创业投资基金绩效评 价中影响其绩效的主要因素, 并结合 DEA-BCC 方法对主要因素进行实证研究 得到了所采用数据大部分引导基金运 营状况有效的结果。

综上，目前国内外对政府创业投资 引导基金建立考核指标体系进行绩效 评价的研究成果较为丰富, 为本文研究 提供了良好的前期研究基础。但由于我 国引导基金发展期不长, 有关绩效评价 的实证研究较少, 并未有较好地评价指 标体系及研究方法。结合我国已有的引 导基金的实际情况，对绩效评价指标体 系的构建及采用更好的分析方法进行 实证研究是本文需要深入思索的重点。

\section{2. 政府创业投资引导基金绩效评价指 标体系构建研究}

\section{1 绩效评价指标体系构建方法}

为促进引导基金稳定持续发展, 科 学合理的绩效评价指标的建立是必不 可少的。还应当结合实际发展状况作出 相应的调整改变以确保绩效评价的准 确性和合理性。政府创业投资引导基金 的绩效评价指标体系构建方法有很多, 比较常用的有三种:

第一, 绩效分析法。绩效分析法主 要是以政府创业投资引导基金为核心, 通过分析引导基金成立规模，基金托管 机构在被投资企业投资占比，被投资的 初创型、种子型企业的财务状况，从而 研究引导基金投资绩效情况。通过绩效 评价研究可以查找出引导基金投资效 率问题所在, 有效评价引导基金发展状 况, 为监管部门提供良好的监督条件。

第二, 宏观研究法。宏观研究法是 站在国家、地区等宏观视角来对政府创
业投资引导基金绩效评价研究。此方法 主要通过研究政府性和商业性基金之 间存此的替代、互补关系，从宏观的视 角分析创业投资资本的供给和需求，来 评价引导基金的绩效成果。

第三，被投资企业分析法。被投资 企业分析法比较受到引导基金投资的 企业和未受到引导基金投资的企业之 间的差别, 分析两者在财务表现和运营 发展上的不同，从而对政府创业投资引 导基金进行绩效评价。此法可有效地分 析得出是否创业投资引导基金可以为 被投资企业带来促进发展的作用。

\section{2 绩效评价指标构建}

政府创业投资引导基金的指标体 系构建的科学程度决定着绩效评价的 有效结果。其内容应该包括: 一是整个 社会资本，有多少是通过引导基金流入 到了创业投资领域; 二是通过政府创业 投资引导的基金中在社会效益和被投 资企业创新创业发展上的促进作用有 多大; 三是创业投资引导基金在不考虑 以营利为前提的基础上, 如何实现稳定 持续增长。在政府创业投资引导基金发 展的过程中应当结合宏观风险因素、地 域影响, 政策环境以及产业导向发展等 构建起防止国有资本与商业性资本流 入发生冲突的有效指标。以政府发起的 创业投资引导基金重点应以政府及国 家政策出发, 来构建较好的评价指标:

一、产业导向效果指标。通过构建 产业导向的效果指标可有效地结合政 策引导资金投入到国家发展方向中去。

二、效益指标。在政策的扶持下， 引入大多社会资本的强势流进, 通过杜 杆效应扩大了基金吸纳的社会资本。 
三、价值指标。社会资本的进入使 风险得到了双方及多方的共同承担，进 而基金的价值变动会影响其持续经营。

四、风险控制效果指标。基金管理 机构自身管理水平及运营效率存在差 异，合理评价和正确选择基金托管机构 有助于控制风险。

\section{3 绩效评价方法}

在我国相关文献研究中一般所涵 盖的绩效分析方法有：因子分析法、 DEA-BCC、聚类分析、模糊 DEA 法、层 次分析法结合 TOPSIS 模型、主成分分 析法等等。张红梅、王哲、陈亚中 (2016) 分析了现有引导基金的特点，构建了引 导基金绩效评估指标体系, 通过选取企 业与对应基金数据采用 DEA-BCC 模型进 行实证分析, 结果表明了引导基金的绩 效评价, 也反应了企业的经营状况 ${ }^{[6]}$ 。

目前, 多数文献集中在指标体系的 构建, 在引导基金绩效评价分析方法上 的实证研究成果也并不多。绩效评价的 关键点在于指标体系的构建以及评价 方法的正确合理选择。本文的创新之处 在于拟采用 DEA 聚类分析法来研究政府 创业投资引导基金的绩效评价，通过提 取基金规模等投入要素以及被投资企 业营利情况作为产出要素, 以此来分析 引导基金的绩效效率。

\section{3. 基于 DEA 聚类政府创业投资引导基 金绩效评价实证分析}

\section{1 DEA 聚类方法简介}

DEA 模型假设有 $n$ 个生产决策单元 $D M U_{j}(j=1,2, \cdots, n)$ ，每个 DMU 都有 $\boldsymbol{m}$ 项输入 $X_{j}=\left(x_{1 j}, x_{2 j}, \cdots, x_{m j}\right)^{r}, S$ 项 输出 $Y_{j}=\left(y_{1}, y_{2 j}, \cdots, y_{s j}\right)^{T}$, 由于在生 产过程中各种输入和输出的地位与作
用不同, 因此, 要对各个指标进行赋权。 设输入和输出的权向量分别为 $v=\left(v_{1}, v_{2}, \cdots, v_{m}\right)^{T}, u=\left(u_{1}, u_{2}, \cdots, u_{s}\right)^{T}$ 。

则效率评价指数可以表示为:

$$
h_{j}=\frac{u^{T} Y_{j}}{v^{T} X_{j}}, j=1,2, \cdots, n
$$

将各决策单元的输入变量和输出 变量进行 “综合” ，把它们看作只有一 个总体输入和一个总体输出。因此, 第 $j_{0}$ 个决策单元 $D M U_{j 0}$ 的效率评估模型为:

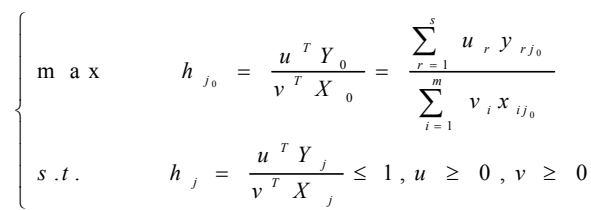

$h_{j 0}$ 越大, 表明 $D M U_{j 0}$ 能够用相对较少 的输入而取得相对较多的输出。

$\mathrm{BCC}$ 模型增添了一个凸性假设：

$\sum_{j=1}^{n} \lambda_{j}=1$, 这时的可能集 $T$ 可描述为:

$$
T_{B C C}=\left\{(x, y) \mid x \geq \sum_{j=1}^{n} \lambda_{j} x_{j}, \sum_{j=1}^{n} \lambda_{j}=1, j=1,2, \cdots, n\right\}
$$

这样就建立了基于生产可能集 $T_{B C}$ 下的 DEA 模 型，即 BCC 模型 :

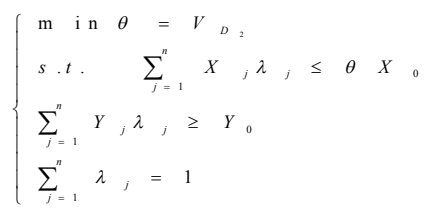

在此基础上, 将原始数据进行处理 以适应 DEA 的有效性原则, 并结合 $\mathrm{K}-$ 均值聚类算法思想开展实证分析研究。

\section{2 指标选取及样本数据}

本文选择了从政府创业投资引导 基金的绩效评价效率入手，分析在参股 基金的机构中选择的投入标的企业是 否达到预期发展，基金的绩效水平是否 可以继续追加投资，研究在参股基金机 
构与被投资企业之间存在的规模效率 问题。随机选取了 2014-2015 年的 40 家政府创业投资引导基金旗下的参股 机构或管理机构的投资规模 $Y_{1}$, 占被投 资企业的股权比例 $Y_{2}$ ，以及相对应的 40 家被投资企业的研发费用 $Y_{3}$ ，员工 人数 $\mathrm{Y}_{4}$, 净利润总额 $\mathrm{X}_{1}$ 以及净利润增 长率 $\mathrm{X}_{2}$, 数据来源是通过 CSMAR 国泰 安数据库与 Resset 金融数据库。本文选 取了 4 个投入指标 ( 3 个主要投入指标, 1 个副投入指标），以及 2 个产出指标。 基金投资规模的多少决定着被投资企 业能够有多少可获投资，规模的大小需 要哪种基金托管机构来管理以提高效 率; 基金投资到企业中的股权占比可通 过分析企业发展状况增减投资比例, 做 出对被投资企业财务状况发展的有效 反应; 被投资企业研发费用考核着这家 企业的发展管理是否合理, 员工人数体 现出人才的得失, 及规模的把握。利润 的增长更加决定着引导基金的持续发 展。

为准确得到实证结果, 本文需要把 存在量纲不同的指标数据进行处理, 使 原始数据是处于正值的范围。本文采用 归一化线性函数法对数据进行无量纲 化处理，使数值在 0 和 1 的区间尽可能 接近到边缘值, 函数关系式如下所示: $A_{i j}=0.01+\frac{c_{j}-x_{j}}{y_{j}-x_{j}} \times 0.99$, 其中 $, x_{j}=\min \left(i_{i}\right), y_{j}=\max \left(\hat{k}_{i j}\right),(i=1,2,3, \cdots, n), A_{i j} \in(0,1$

\section{3. $3 \mathrm{DEA}$ 聚类结果}

本文采用 DEA 聚类分析政府创业 投资引导基金的绩效评价的综合效率， 将原始数据 40 家被投资企业与与之对 应的基金管理机构的投入、产出指标载
入到 DEAP 版本 2.1 软件中进行运算, 可得到相应的 40 个原始数据集的综合 效率、纯技术效率、规模效率。

DEAP 软件分析的结果中会存在规 模收益递增、规模收益不变、规模收益 递减三类，而在数据分析结果中可看到 不存在规模收益递减的引导基金。共有 11 家引导基金参股企业出现了规模收 益不变, 其余都出现规模收益递增的状 态。根据以上结果再通过 $\mathrm{K}$ 均值聚类进 一步分析, 通过 SPSS 软件得出相应的 聚类结果，见表 $1 、$ 表 2。

表 1 最终聚集中心

\begin{tabular}{|c|c|c|c|}
\hline & \multicolumn{3}{|c|}{ 聚集 } \\
\hline & 1 & 2 & 3 \\
\hline crste & 0.322 & 0.273 & 0.852 \\
\hline vrste & 0.702 & 0.344 & 0.941 \\
\hline scale & 0.462 & 0.793 & 0.903 \\
\hline
\end{tabular}

表 2 变异数分析

\begin{tabular}{|c|c|c|c|c|c|c|}
\hline & \multicolumn{2}{|c|}{ 聚集 } & \multicolumn{2}{|c|}{ 错误 } & F & sig \\
\hline & 均值 & & 均值 & & & \\
\hline & 平方 & $\mathrm{df}$ & 平方 & $\mathrm{df}$ & & \\
\hline crste & 1.56 & 2 & 0.019 & 37 & 82.734 & 0 \\
\hline vrste & 1.29 & 2 & 0.01 & 37 & 131.923 & 0 \\
\hline scale & 0.56 & 2 & 0.015 & 37 & 36.922 & 0 \\
\hline
\end{tabular}

根据表 1 聚类中心得出的结果可有 效将 40 家引导基金绩效结果进行聚类, 在聚类结果中, 通过对比聚类中心和原 始数据, 将聚类分析得出的三类结果分 别对应表述为规模收益强递增、规模收 益稳递增、规模收益弱递增及不变。在 表 2 中, 三个效率指标 sig 值均小于 0.05 , 结果表明数值结果的显著性。 
分析结果表示在第一类企业中，可 适当加大投入规模, 吸引外资的加入, 引进优秀人才, 适量增加研发费用, 引 导基金可增加股权比例以鼓励被投资 企业更好发展；在第二类企业中，可通 过调节投入产量的比例以及良好的人 员安排，提高发展效率; 而在第三类中， 说明这些企业在现有指标分析下，基本 接近投入与产出效率最大化。

DEAP 版本 2.1 的软件分析得到某 些基金所投资的企业中，并未实现基金 产出指标的有效目标值。除规模收益不 变的被投资企业，其余在投入量指标中 都有出现松弛变量值, 主要集中在基金 成立规模以及被投资企业员工人数上, 在基金投入的过程中要注意规模的把 控，而被投资企业也应适当精简员工， 引进人才提高效率。大部分的基金绩效 评价结果都比较良好, 但还有待提高综 合效率指标，以稳定引导基金的持续发 展。

\section{4. 结束语}

本文旨在为政府创业投资引导基 金构建更好的绩效评价体系。通过运用 $\mathrm{DEA}$ 聚类方法，对 40 家引导基金管理 机构与对应的被投资企业进行了实证 分析, 建立了新的投入、产出分析指标, 得到引导基金绩效评价的有效 DEA 评 价值, 并以 $\mathrm{K}$ 均值聚类得出分类结果。 实证表明了 DEA 聚类在引导基金上的 适用性和有效性, 为构建科学的绩效评 价指标分析提供了新的方法和思路。 DEA 聚类法相比其他分析方法虽有优 势, 也存在局限, 使得本文在不同的选 取指标下, DMU 所对应的 DEA 有效性 评价结果是不一样的, 通过归一化线性
函数处理的非正数的数据中多少也会 使得结果产生一定差异。那么在政府创 业投资引导基金的绩效评价指标选择 上还有待进一步研究。

\section{参考文献}

[1] David B. Audretsch, Albert N. Link, John T. Scott. Public/Private Technology Partnerships: Evaluating SBIR-Supported Research[J].Research Policy, 2002,31(1):145-158.

[2] Luukkonen Terttu, Deschryvere Matthias, Bertoni Fabio.The value added by government venture capital funds compared with independent venture capital funds[J].Technovation, 2013,33(4-5): 154-162.

[3] 李洪江,鲍晓燕.政府导向型创业 投资基金绩效评价研究 [J]. 商业研 究,2011,(6):112-116.

[4] 王哲. 基于因子分析和 DEA 模型 的政府创业投资引导基金绩效评 价研究 $[\mathrm{A}]$. 中国管理现代化研究 会、复旦管理学奖励基金会. 第十 届（2015）中国管理学年会论文 集[C].中国管理现代化研究会、复 旦管理学奖励基金会:,2015:7.

[5] Zhang H M, Chen Y Z, Wang Z. Research on the performance evaluation of government venture capital fund based on factor analysis and DEA model[J]. Journal of Risk Analysis \& Crisis Response, 2016, 6(1):15. 